\title{
The Latin Music Mood Database
}

\author{
Carolina L. dos Santos and Carlos N. Silla Jr*
}

\begin{abstract}
In this paper we present the Latin Music Mood Database, an extension of the Latin Music Database but for the task of music mood/emotion classification. The method for assigning mood labels to the musical recordings is based on the knowledge of a professionally trained Brazilian musician and the identification of the predominant emotion perceived in each song. We also present an analysis of the mood distribution according to the different genres of the database.
\end{abstract}

Keywords: Music information retrieval; Ethnic music; Music emotion

\section{Introduction}

Within the Music Information Retrieval (MIR) community, one particular task that has become increasingly popular is the task of music emotion (or mood) classification. Over the years, several approaches have been used to label different music databases with emotion/mood labels. Some of the approaches used so far vary from the manual assignment of categorical emotion labels [1-3] to user-listening tests [4-8]. There has also been some efforts to automate [9] and semi-automate [10] the mood assignment processes.

In this paper, instead of creating a novel database and using one of the previous approaches to label it with emotion labels, we decided to apply emotion/mood labels to an already existing database, namely the Latin Music Database (LMD) [11]. The LMD was originally developed for the task of automatic music genre classification and contains 3136 songs from ten different Latin music genres. One of the main differences between the LMD and other databases is that the genre labels were assigned to each song in the database by two ballroom and Brazilian cultural dances teachers with over ten years of experience.

The main contribution of this paper is to present the Latin Music Mood Database, which is an extension of the LMD where each song in the LMD has one mood label associated with it. The process of assigning mood labels is presented in Section 2. In Section 3 we present a data analysis of this novel database. In Section 4, we present the related work, and in Section 5, we present the conclusions of this work.

*Correspondence: carlosjunior@utfpr.edu.br

Computer Music Technology Laboratory at the Federal University of Technology of Paraná, Av. Alberto Carazzai, 1.640, 86300-000 Córnelio Procópio, Brazil

\section{The process of assigning music emotion/mood labels}

The first challenge when creating a novel emotion or mood database is what to label as ground-truth. In the case of music emotion classification, the ground-truth labels can be related to the emotions perceived by listening to the songs or evoked by listening to the songs [12]. In this work, we have chosen to label the predominant emotion perceived in each song of the Latin Music Database [11].

The second challenge when creating a novel (or applying new labels to an existing database, as in our case) is which approach to use to conceptualise the concept of emotion in music [12]. Some of the previous work have used categorical labels while others have used emotions based on emotional plane. As we shall see in Section 4, there is no consensus among the Music Information Retrieval community about which approach should be used, or, in the case of categorical labels, how many labels and which labels should be used.

For these reasons, in this work, we asked the help of a professionally trained Brazilian Musician to help us with the assignment of mood labels to each song in the LMD, creating the Latin Music Mood Database. It should be noted that the expert is an acoustic guitar player who is also fluent in both Portuguese and Spanish languages. In order to label the songs, we had a few meetings with the expert where we discussed the current labelling approaches used in the related works. After these meetings, the expert suggested that six emotions could be used to map the predominant emotion encoded in each song of the LMD. The expert also felt that these emotions are reminiscent of the emotional plane provided by the Affective Circumference Model of Watson and Telegen

\section{Springer}

(C) 2015 dos Santos and Silla. Open Access This article is distributed under the terms of the Creative Commons Attribution 4.0 International License (http://creativecommons.org/licenses/by/4.0/), which permits unrestricted use, distribution, and reproduction in any medium, provided you give appropriate credit to the original author(s) and the source, provide a link to the Creative Commons license, and indicate if changes were made. 


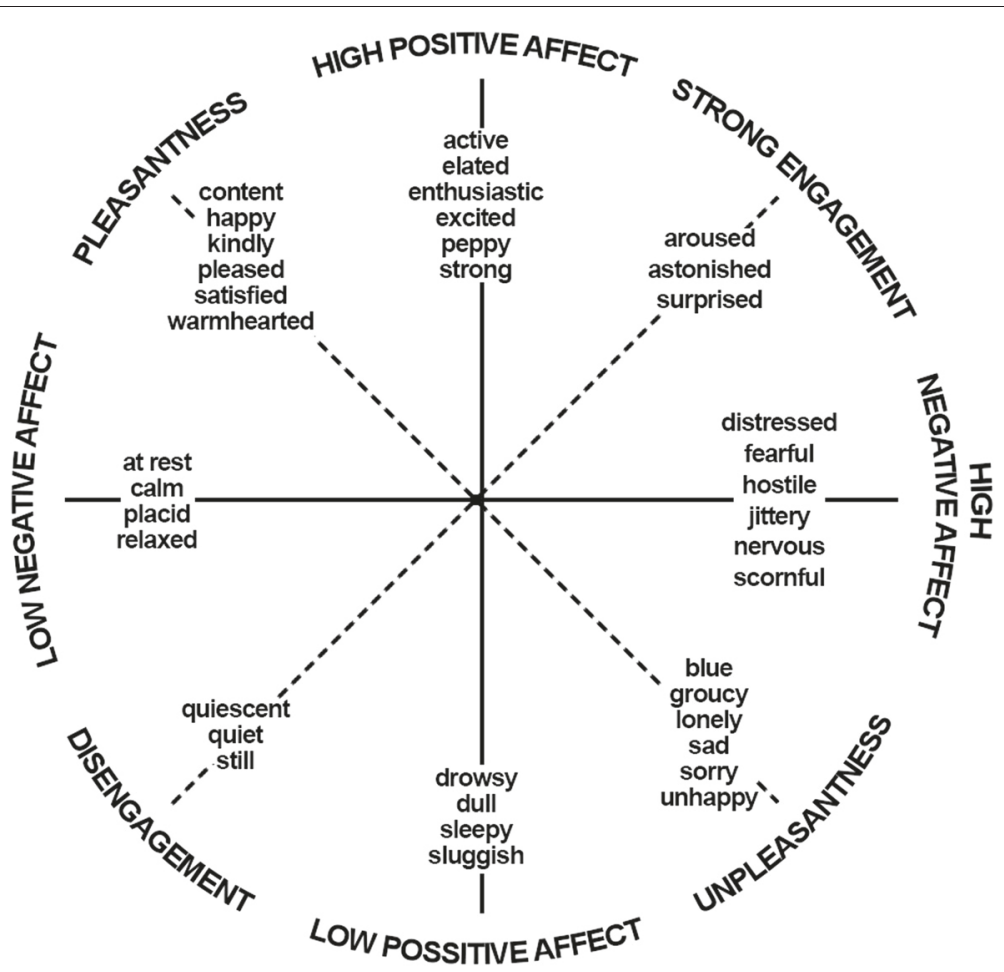

Fig. 1 Affective circumference of Watson and Telegen [13]

[13] (presented in Fig. 1). An additional reason for asking the help of an expert is that the LMD is one of the few music databases that had its music genre labels assigned by experts and we wanted to keep the LMD that way (i.e., a database whose labels have always been assigned by experts).

In total, the expert assigned one of the following six emotions to each song:

- Tristeza (Sadness): grief, melancholy, sorrow, or distress. Discouragement or frustration towards someone or something. Sadness may be the result of emotions like selfishness, insecurity, low self-esteem, jealousy, immaturity, fear, and disillusionment [14]. In Fig. 1, the expert thought that this emotion was related to Unpleasantness.

- Decepção (Disappointment): Feeling of dissatisfaction that arises when expectations about something or someone do not come to fruition. It is similar to repentance, but differs from it in that repentance is focused on the choices people have that lead to a negative result, while disappointment is focused on the result itself [15]. In Fig. 1, the expert thought that this emotion was related to the High Negative Affect.

- Amor (Love): The concept of love used in this work is based on the concept from the Trovadorism (XII
Century) until the Romanticism period (XVIII and XIX) will be used as basis for classification. When a person is in love, a being has no more importance without their muse to worship. Supplication to a higher (spiritual) being leads to faith, i.e., a kind of love that is from the supplication of the individual to its creator or as from child to parent [16]. In Fig. 1, the expert thought that this emotion was related to the Strong Engagement.

- Excitação/Entusiasmo (Excitement/Enthusiasm): is a state of great excitement and joy, optimism.

Table 1 Number of songs of each emotion/genre

\begin{tabular}{lllllll}
\hline & Joy & Sadness & Love & Disappointment & Enthusiasm & Passion \\
\hline Axé & 53 & 8 & 41 & 8 & 127 & 62 \\
Bachata & 4 & 59 & 123 & 2 & 1 & 119 \\
Bolero & 15 & 57 & 114 & 1 & 7 & 104 \\
Forró & 48 & 19 & 88 & 11 & 65 & 79 \\
Gaúcha & 105 & 34 & 30 & 3 & 104 & 28 \\
Merengue & 27 & 49 & 64 & 6 & 50 & 111 \\
Pagode & 56 & 30 & 98 & 5 & 25 & 87 \\
Salsa & 25 & 60 & 90 & 3 & 19 & 102 \\
Sertanejo & 26 & 66 & 67 & 3 & 59 & 87 \\
Tango & 78 & 88 & 60 & 55 & 28 & 93 \\
\hline
\end{tabular}




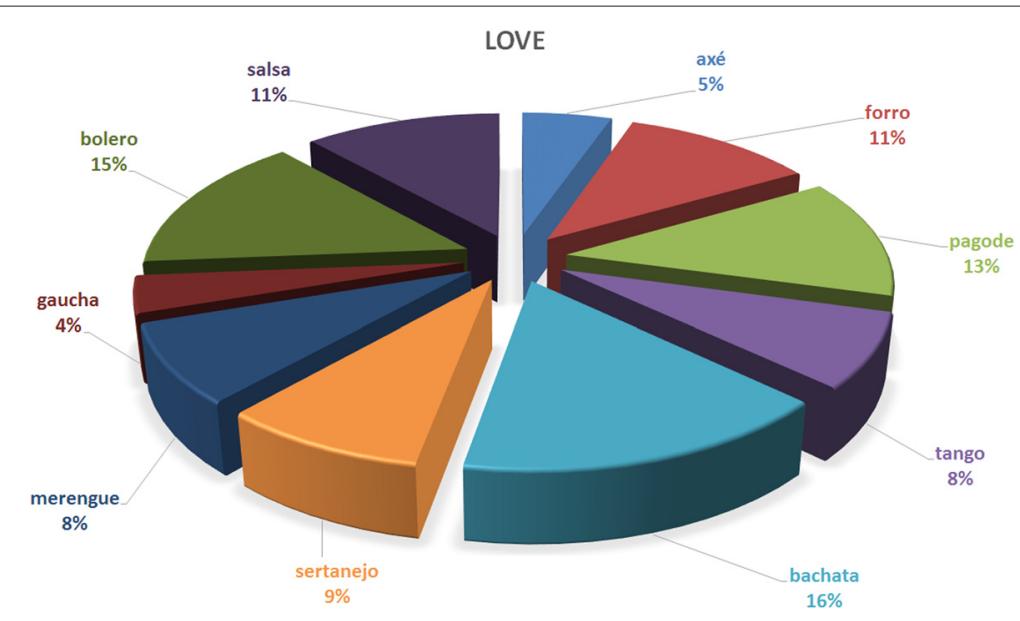

Fig. 2 "Amor" (Love)

There are two kinds of excitement: endogenous and exogenous. A kind of the enthusiasm depends on an external reason to be having this feeling, and the other depends on itself [17]. In Fig. 1, the expert thought that this emotion was related to the High Positive Affect.

- Paixão (Passion): is a momentary emotion that might disappear quickly. It is related to the carnal and mental desires [18]. In Fig. 1, the expert thought that this emotion was related to the pleasantness.

- Alegria (Joy): is a primary emotion, it comes through our five senses as a feeling of acceptance/ resignation/satisfaction/achievement [19]. It is usually found in songs based on a day-to-day narrative, singing about how good your life or your day is, among others. In Fig. 1, the expert thought that this emotion was related to the Low Negative Affect.

After the tagging process we asked the expert what approach he used to identify and tag each song with its predominant mood label. The process used by the expert consisted of listening to the full audio recording paying attention to the song melody and the song lyrics (if the song was not instrumental). According to the expert, there were cases where identifying the predominant emotion was not clear. This might be explained by the fact that while some songs should sound in a particular way (e.g., sad) they can be made merrier depending on how it is performed. When the expert was in doubt about which label to assign to a particular song, she would consult other colleagues for a second or third opinion.

\section{Data analysis}

In this section, we are interested in understanding the music genre and mood distribution in the Latin Music Mood Database after the emotion/mood labels were assigned. This section is divided in the analysis by mood and by music genres. The overall numbers are presented in Table 1.

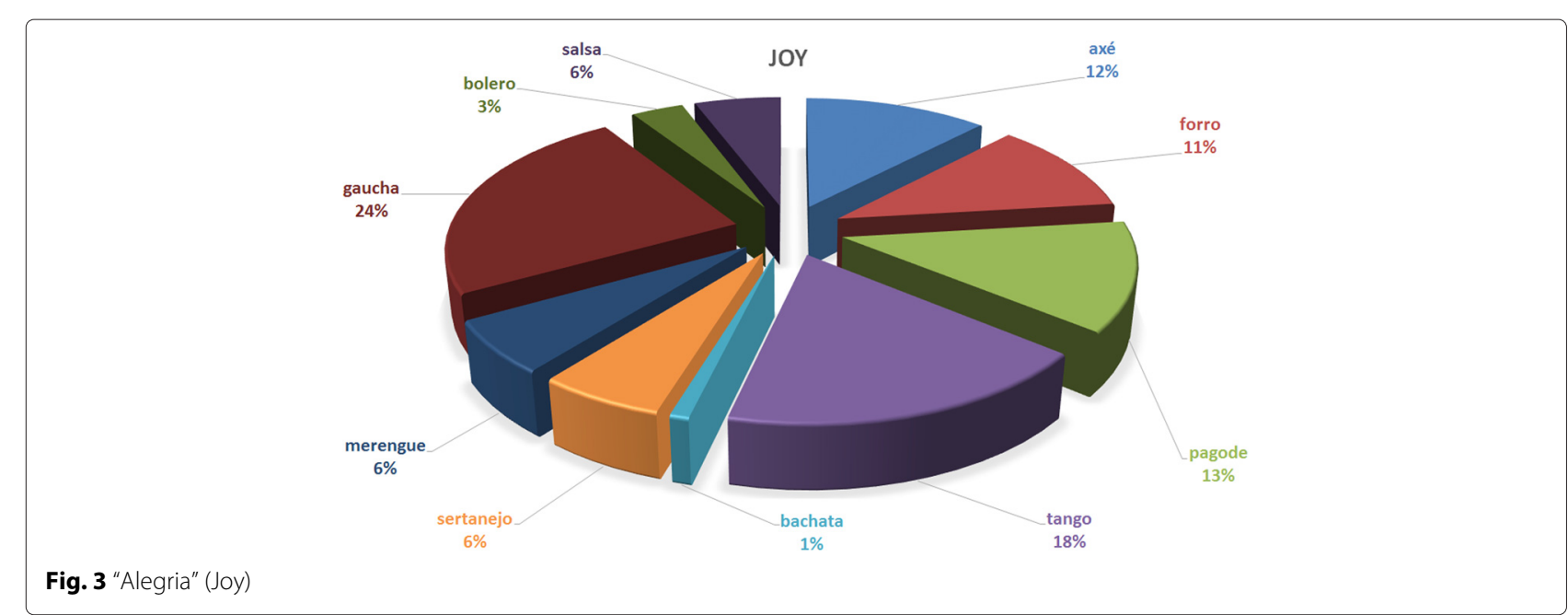




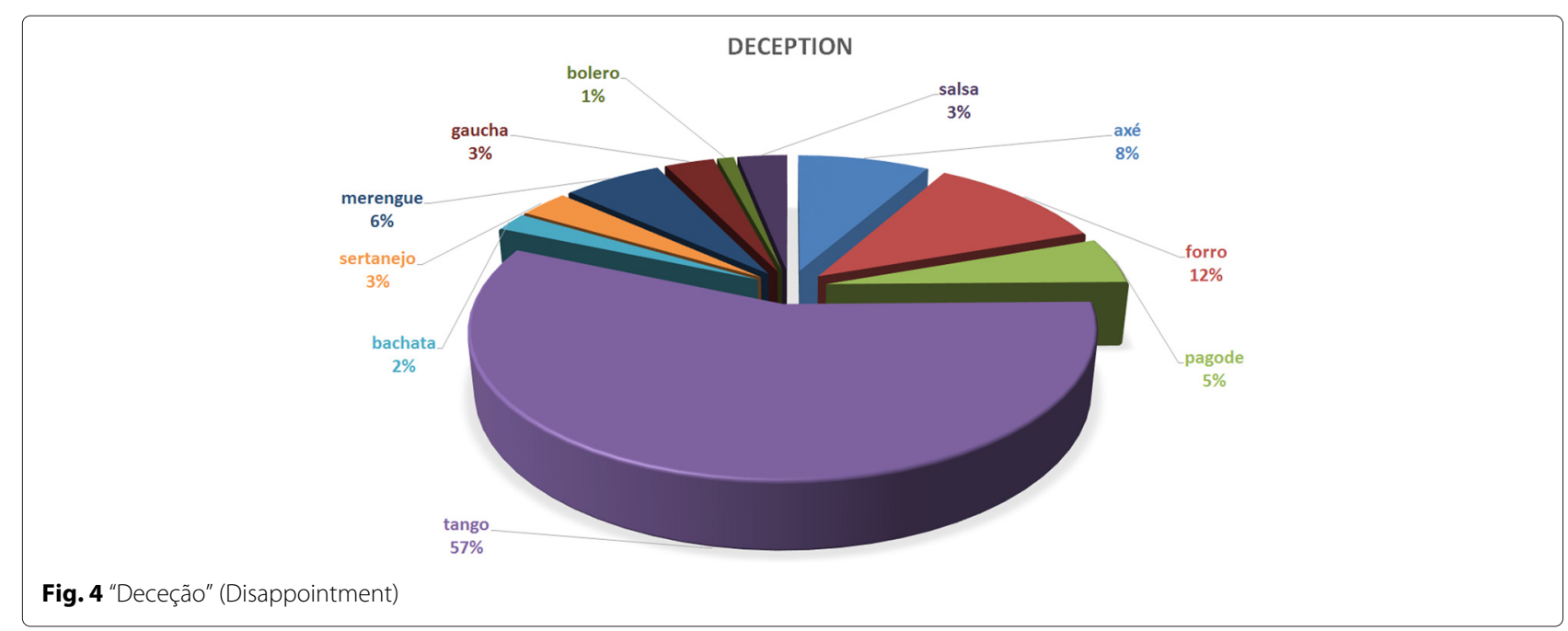

\subsection{Analysis by mood}

In this section, we present an analysis of each mood in respect to the ten different music genres presented in the LMD. Furthermore, we want to verify whether there is a direct correlation between mood and genre and whether or not some music genres have only one predominant emotion. For a detailed description of each of the music genres of the LMD, the interested reader is referred to the glossary of [11].

The first emotion that we look at is Love (Presented in Fig. 2). The analysis of Fig. 2 shows that all ten music genres have songs about love, being Bachata (16\%) the highest one and Gaúcha (5\%) the lowest one. However, note that this analysis is done considering only the existing songs in the database and may not be used to infer global assumptions about these music genres. However, the fact that Bachata had the high proportion of love songs came to us as a surprise as we thought it might have been Tango.
The second emotion that we look at is Joy (Presented in Fig. 3). The analysis of Fig. 3 shows some interesting results. First, that the Brazilian Music Genre Gaúcha is the highest one (24\%). This might be explained by the fact that this particular style, which is more popular in the Southern part of Brazil, usually has many strong nationalist songs about pride as being Gaúchos and their beautiful lands. Second is that some genres have a low value of songs with Joy, such as Bachata (1\%) and Bolero (3\%).

The third emotion that we look at is Disappointment (Presented in Fig. 4), and it is a popular "theory" that this emotion is usually related to Tango songs. The analysis of Fig. 4 shows that this popular theory is confirmed, at least for the Tango songs in the LMD, as they correspond to $57 \%$ of the songs assigned the Deception mood label.

The fourth emotion that we look at is Sadness (Presented in Fig. 5). The analysis of Fig. 5 shows that

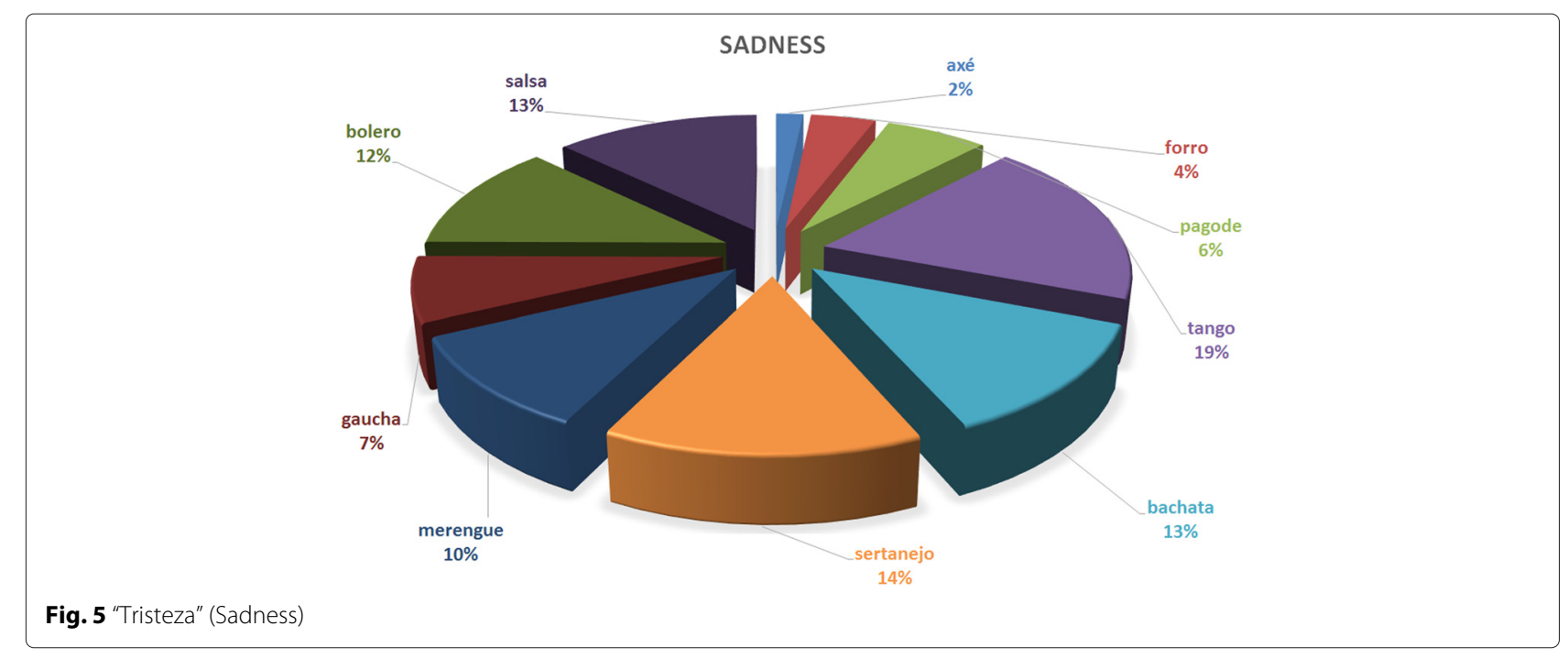




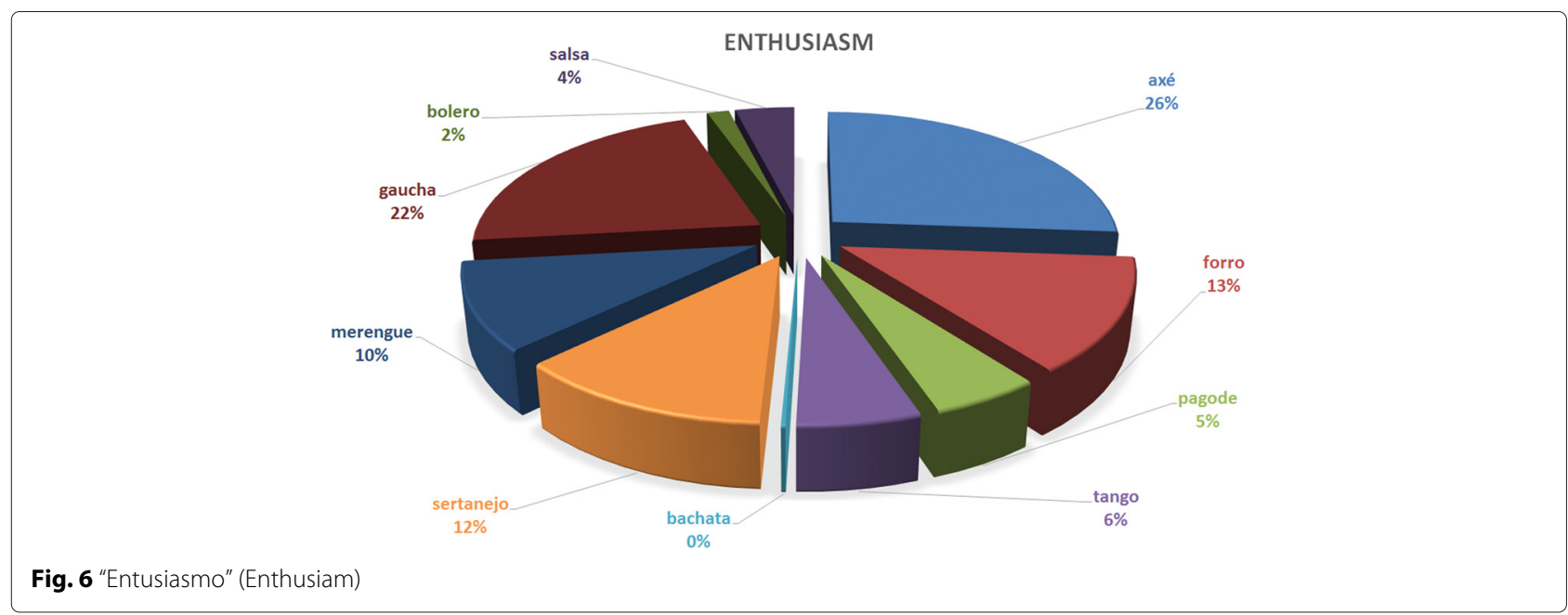

Tango songs are also sad songs and correspond to $19 \%$ of the songs which have been assigned as sad from the different genres.

The fifth emotion that we analyze is the Enthusiasm/ Excitement (Presented in Fig. 6). The analysis of Fig. 6 shows that, as expected, Axé songs are predominant in this emotion. This is explained by the fact that this particular music genre is very popular in Bahia, Brazil, the land where "The Carnival" is known for lasting all year.

The last emotion we analyze is Passion (Presented in Fig. 7). The analysis of Fig. 7 shows that, with the exception of Gaúcha, most music genres have a similar proportion in this mood.

The overall analysis of all these results shows that there is not an exact mapping between genre labels and $\operatorname{mood} /$ emotion labels. However, it leaves us wondering how much each emotion is present within each of the ten music genres of the LMD. This analysis is presented in the next section.

\subsection{Analysis by genre}

In this section, we want to understand how much each mood is presented in each of the music genres in the LMD.

The Tango music genre in the LMD (Fig. 8) is mainly composed of songs that elicit passion (23\%), sadness (22\%), joy (19\%), love (15\%), and disappointment (14\%). It is noteworthy to clarify that in the analysis presented in Section 3.1, where the songs from the Tango music genre dominated the Disappointment emotion (Fig. 4), that does not necessarily mean that all songs in the Tango music genre elicit this mood. It only means that within the set of songs that were assigned, the disappointment emotion label, the ones that were from the Tango music genre were the majority ( $57 \%$ ) of it.

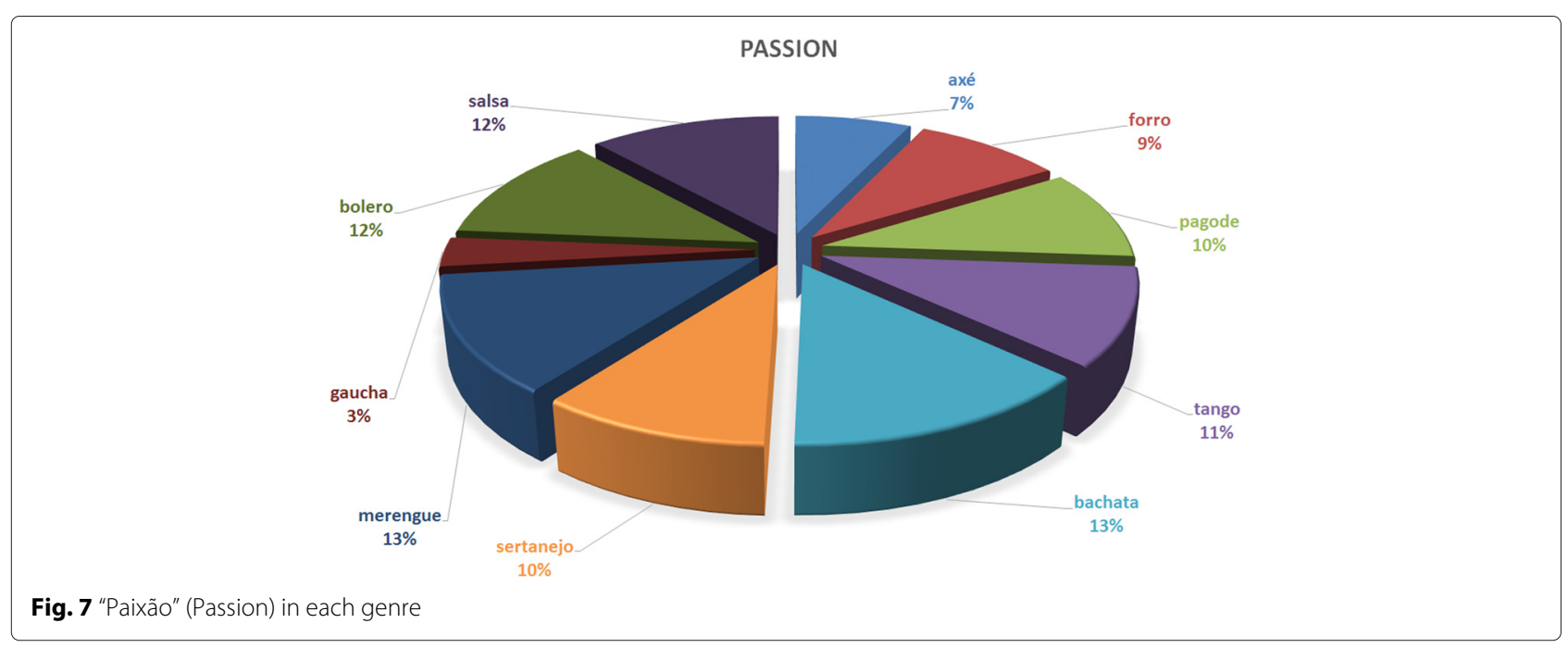




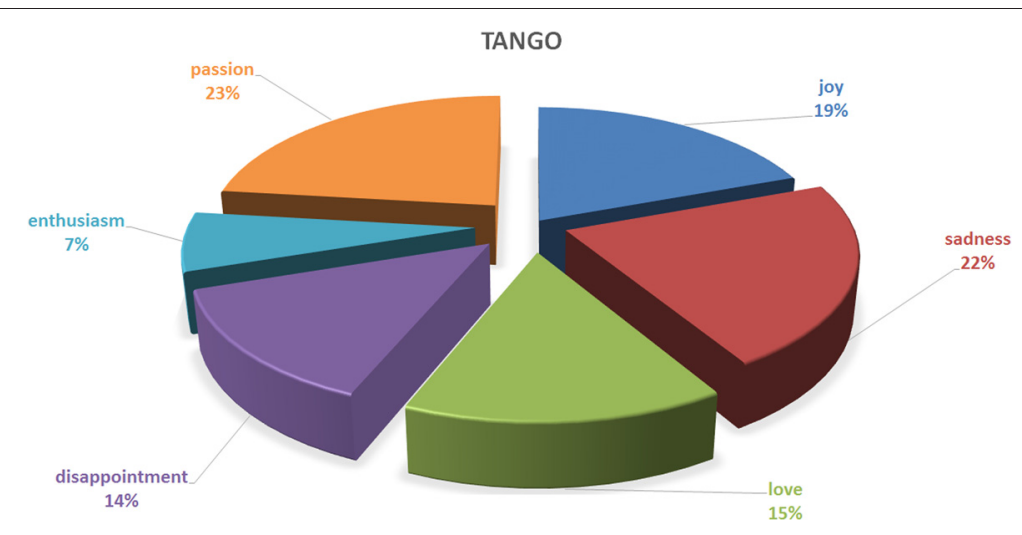

Fig. 8 Proportional analysis of each mood in respect to the Tango music genre

For the other Latin music genres (Bachata, Bolero, Merengue, Salsa presented in Figs. 9, 10, 11, and 12) which are popular in different countries in Latin America and that are often danced by couples, it is no surprise that their songs are mainly about love $(40,38,36$, and $30 \%$ for Bachata, Bolero, Merengue, and Salsa, respectively) or passion $(39,35,36$, and $34 \%$ for Bachata, Bolero, Merengue, and Salsa, respectively).

For the Brazilian music genres that are also danced by couples (Forro, Pagode, Sertanejo), the analysis of Figs. 13, 14 , and 15 shows that they also have a large part of their songs about love $(28,32$ and $28 \%$ for Forro, Pagode, Sertanejo respectively) or passion $(25,29$, and $21 \%$ for Forro, Pagode, Sertanejo, respectively).

There are two music genres that do not follow the trend of having songs mainly about love or passion. The first one is the Gaucha music genre (presented in Fig. 16). This particular music genre is mainly composed of songs that elicit joy (35 \%) and enthusiasm (34\%).
The second one is the Axé music genre (presented in Fig. 17). This music genre originated from Brazil, and it is often associated with the Carnival and is also very popular in the northeast all year. It is mainly composed of songs that elicit Enthusiasm ( $42 \%$ of the songs).

\section{Discussion and related work}

Broadly speaking, there are two perspectives for the task of music emotion classification such as: a MIR perspective and a music cognitive (psychological) perspective. An interesting discussion about the differences between these two perspectives (and not limited to the task of music emotion classification) can be found in [20]. In this section, we present the related work from each perspective.

\subsection{MIR perspective}

The task of music mood/emotion classification is becoming increasingly important with the MIR research

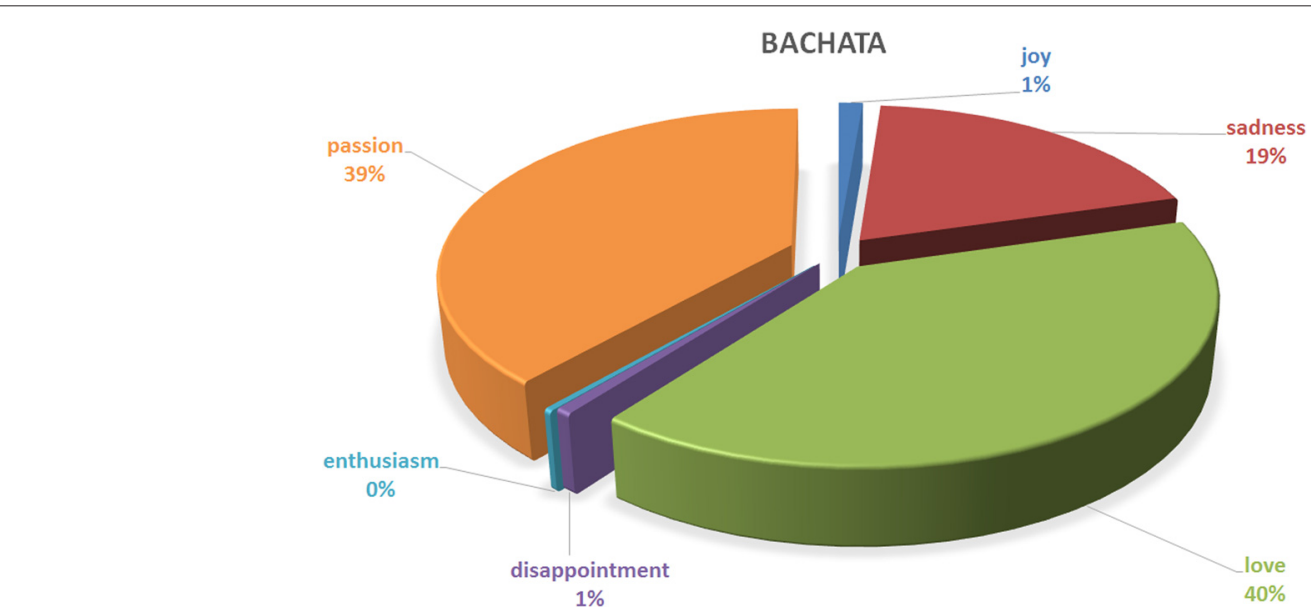

Fig. 9 Proportional analysis of each mood in respect to the Bachata music genre 


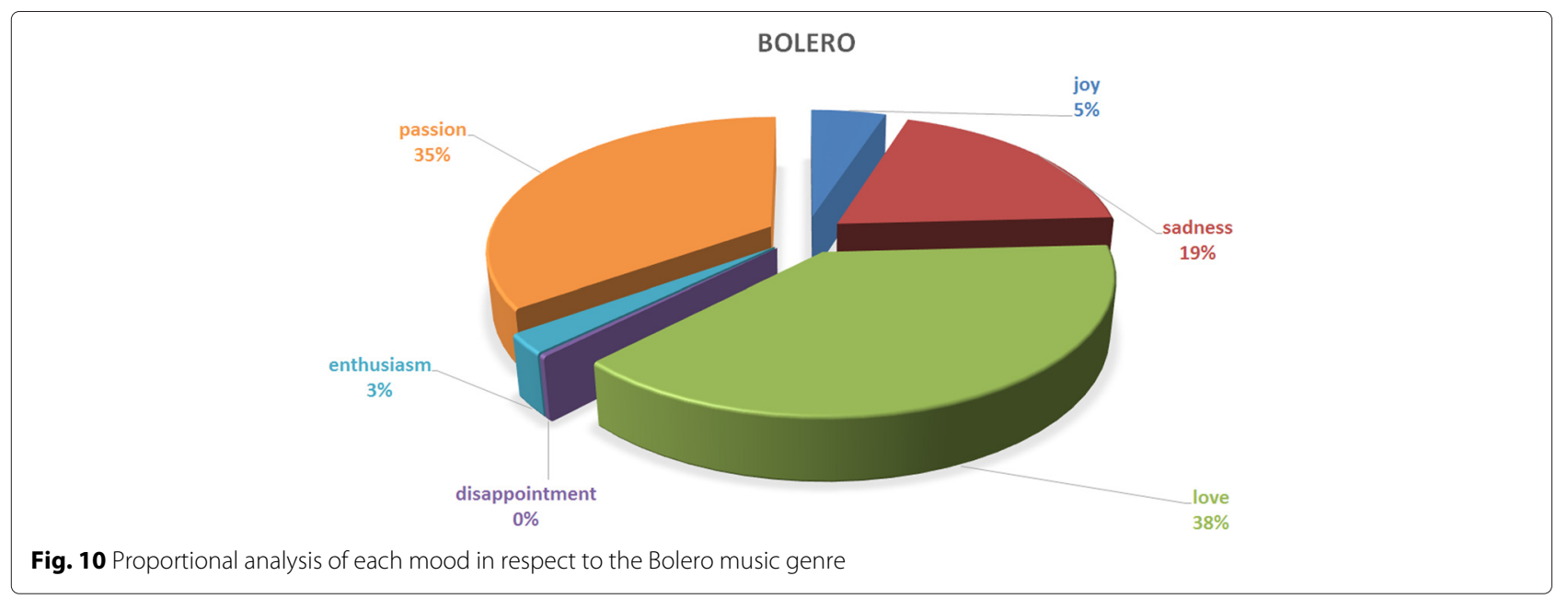

community. In [1], the authors also used a categorical approach to classify a database of 1000 songs in English into the following eight categories: happy, sad, angry and relaxed, not happy, not sad, not angry, and not relaxed. In order to label the songs with one of the four categories, they have the tags provided by the Last.FM website and then asked the annotator to listen $30 \mathrm{~s}$ of the songs and make a decision if the label was appropriate.

In [2], the authors use a database of 2653 Chinese pop songs that are classified into the following two categorical emotions: light hearted and heavy-hearted. Unfortunately, no information about how these genre labels were applied to the dataset are presented.

In [3], a dataset of 1903 Chinese pop songs is used. The songs are also labelled with the following two categorical emotion labels: love and lovelorn.

In [21], the authors perform a study on cross-cultural music mood retrieval experiments by using the mood categories used in MIREX 2010 for English language songs and applied them to Chinese songs. The genre labels of the dataset are based on the most popular labels on the allmusic.com website.

In [4], a dataset of 50 Chinese pop songs was labeled through a subjective test conducted by eight participants. As emotion labels, they have used four categorical classes that are equivalent to each quadrant of the Thayer's arousal-valence emotion plane.

In [7], the authors used a dataset provided by a small company for providing music applications, namely Crayonroom. The song/mood pairing comes from their Moody application which lets users tag songs in iTunes in order to generate mood-based playlists. The users tag the mood using one of the 16 available colors.

In [5], the authors evaluated their system on the Now That's What I call Music! (NTWICM) database. The NTWICM contains 2648 songs annotated by four listeners on 5-point scales for perceived arousal and valence for each song.

In [9], the authors used a dictionary-based approach to automatically measure the average valance and arousal of

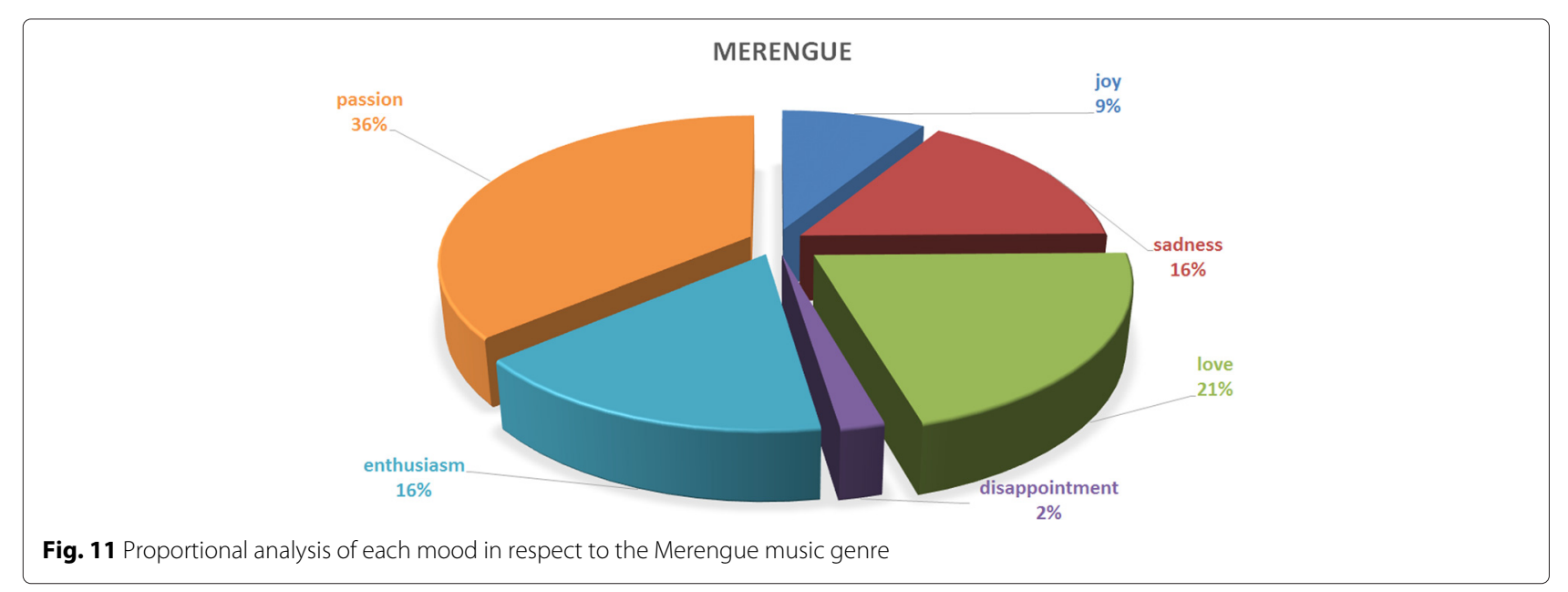




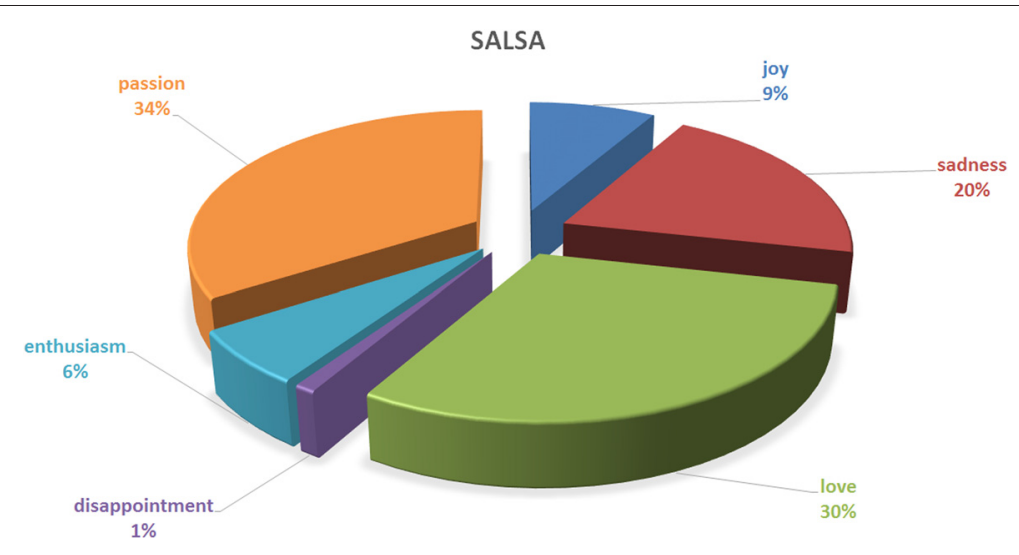

Fig. 12 Proportional analysis of each mood in respect to the Salsa music genre

a song. As their dictionary, they have used the Affective Norms for English Words (ANEW) which contains ratings of 1030 words on pleasure, arousal, and dominance collected by psycholinguistic experiments [13].

In [8], the authors use the amazon mechanical turk to have amateurs label their dataset of 100 popular songs (e.g., Let it Be by The Beatles) into the six emotions: Anger, Disgust, Fear, Joy, Sadness, and Surprise.

In [6], the authors also adopt the Thayer's arousalvalence emotion plane and derive the following four categorical classes: Angry/Anxious; Happy/Exciting; Sad/Bored ; Relaxing/Serene. They perform their experiments with 500 Chinese pop songs, and the emotions of the songs were labelled through a subjective test conducted by eight participants.

In [22], the authors created a database of 943 Greek songs from various genres and use the Thayner arousal valence emotion model. The authors state that the labels were manually assigned; however, no mention about how many users and their music level proficiency are provided.
In [10], the authors created a mood dataset of 4197 songs that have both lyrics and at least one tag from the Last.FM website by using an automated process. The process they used was based on using the Wordnet-Affect to match the unique tags from Last.FM to a collection of originally over 20,000 songs. After they encountered 348 matching words, they manually inspected and removed the tags that were not related to mood and also the ambiguous tags such as love (i.e., the user could have tagged the song a love because it is either a love song or because the user loves that song). They further used Wordnet to group the tags that belonged to the same synset. In the end, they ended up with 18 mood categories containing 135 tags.

In [23], the authors use a dataset rated by human listeners and they could label the songs to at least one of the following 12 moods: Sad, Calming, Arousing, Powerful, Tender, Cheerful, Carefree, Aggressive, Peaceful, Emotional, Loving, Restless.

In [24], the authors perform studies using MRI scans to classify the listened songs into happy and sad songs.

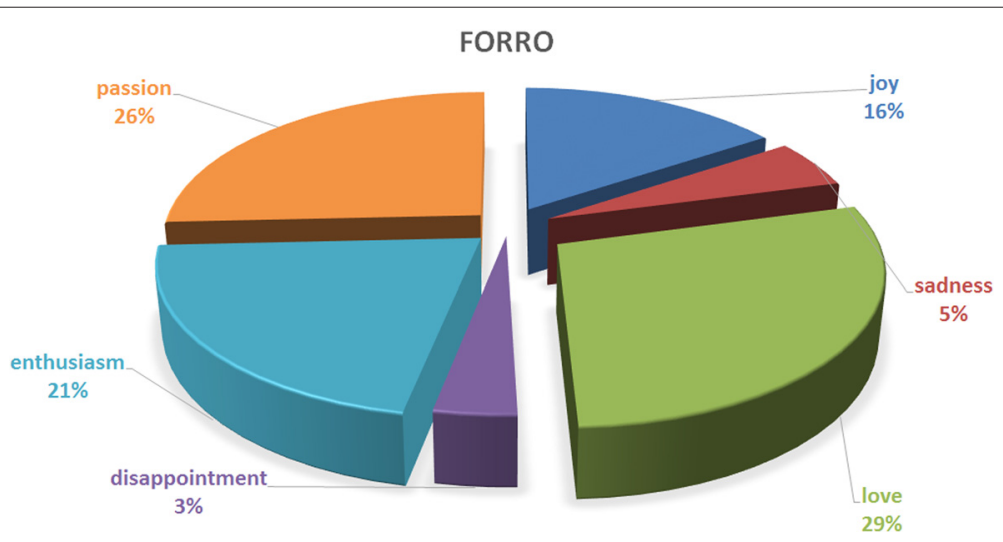

Fig. 13 Proportional analysis of each mood in respect to the Forro music genre 


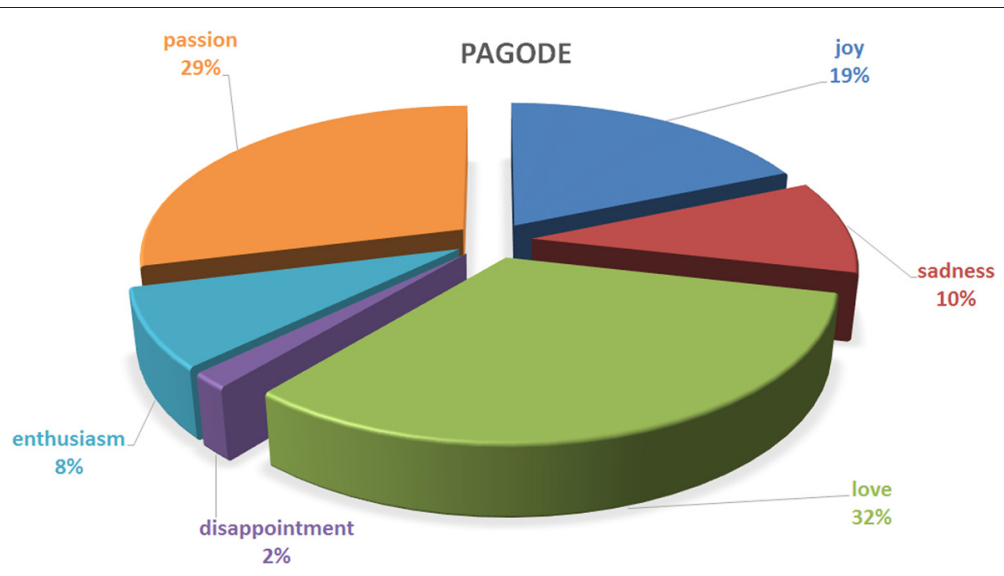

Fig. 14 Proportional analysis of each mood in respect to the Pagode music genre

\subsection{Psychological perspective}

The analysis of the related work from the MIR perspetive shows that different authors have used different mood models and different approaches to label them. However, this paper is the first (to the best of the authors knowledge) to have a mood database labeled by a professionally trained musician. This approach can raise some concerns as to whether or not a professional musician can correctly identify the perceived emotions in the songs. This and some related issues has been investigated in some works from the psychology literature, and we present them in this section.

In the study performed by [25], there were differences in the affective response of trained musicians in contrast to non-musicians. One of the plausible explanations, presented in the study, for the different responses was that the training and past listening experiences of trained musicians make them more likely to respond analytically to music information. However, the study by [26] reports that in their experiments music experts and non-musicians ascribed similar emotion to music pieces. In a more recent study by [27], it was shown that it is not which song you play but rather how the song is played that affects the perception of emotion by non-musicians. In [27], they also show that the timbre of the musical instruments affects the perception of emotion conveyed by the melody.

Another important aspect to take into account is whether or not the song is accompanied by lyrics and if the presence of lyrics affects the perception of emotion. This issue was addressed in the work of [28] that concluded that lyrics influence the affective response by its listeners. In the work of [29], several experiments on the perception of emotional expression in musical performance were performed. One of their findings is that musical training affected the way participants rated the emotionality of the stimuli. Their obtained results suggest that in one hand non-musicians judge a greater proportion of their emotional judgements on the tonality of the music piece rather than on the expressivity levels, while on the other

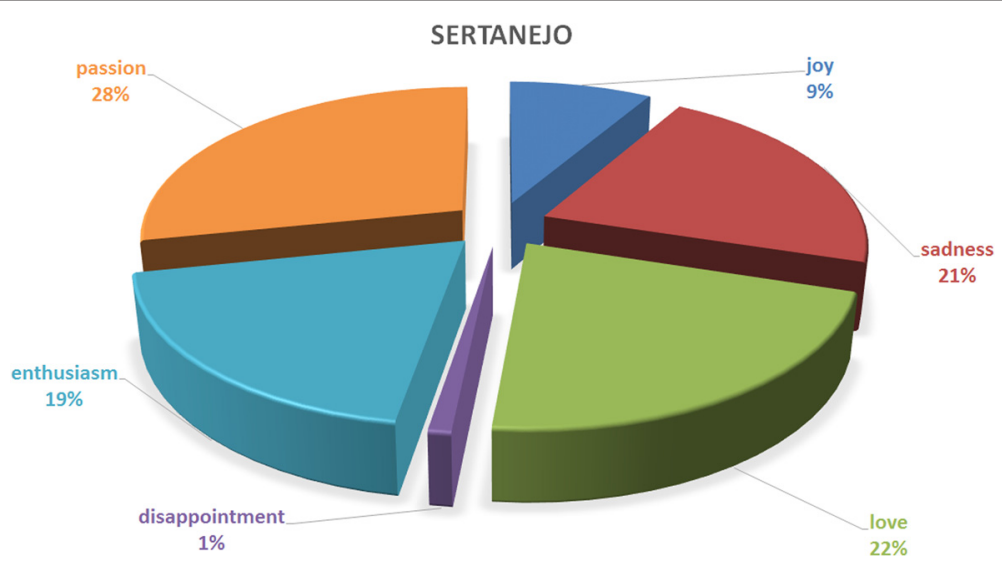

Fig. 15 Proportional analysis of each mood in respect to the Sertanejo music genre 


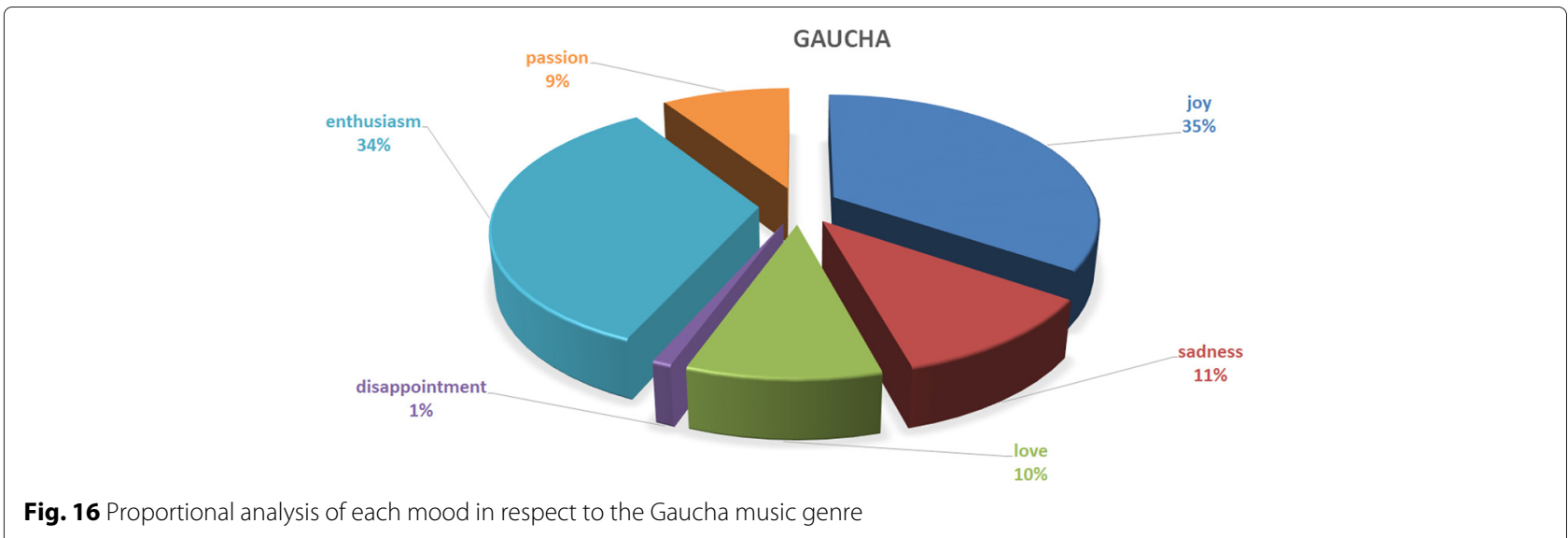

hand, musicians base their judgements primarily on the expressivity levels.

A recent review by [30] on the issue of Music and Emotion classification from a psychological perspective shows that only 6 out of 251 (i.e., $4 \%$ ) reviewed works dealt with Ethnic music. To the best of our knowledge, none of them used any of the Latin music genres used in this work. Also, according to [31], in a cross-cultural music studies, the emotional expressiveness of music arises from a combination of culture-specific and universal cues. Therefore, having a professional musician with the same cultural background of the music genres in the LMD is an important aspect of the developed database. Furthermore, a future research direction might be to use the developed database in cross-cultural studies.

\section{Conclusions}

In this paper, we presented the Latin Music Mood Database which is an extended version of the LMD but with one emotion label, representing the predominant emotion perceived in each song of the LMD.
Our data analysis of this novel database has shown that there is not a clear one genre equal to one type of emotion/mood as people might think at first. However, it was clear that the majority of the music genres present in the LMD had at least $25 \%$ of their songs about either love or passion. We believe that this novel Latin Music Mood Database might prove useful for the Music Information Retrieval research community. Future research directions include conducting listenings tests in order to verify if the predominant emotions are also the same emotions perceived by the listeners and to verify whether or not the use of affective dictionaries can also be used to identify the predominant emotions of songs.

A few distinct characteristics of the Latin Music Mood Database are as follows (to the best of the authors knowledge): 1) It is the first music emotion/mood database that has been manually labeled by a music expert; 2) It is also the first music emotion database that was developed for Latin Music genres. Previous work on this field has used songs in English and Popular Chart Songs [5, 8], Chinese Songs [2-4], or Greek Songs [22].

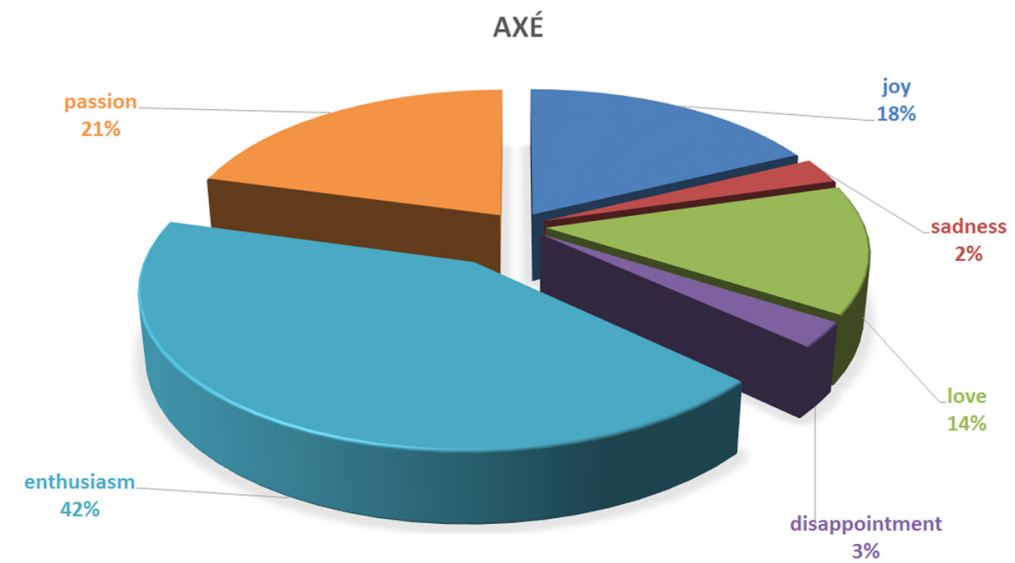

Fig. 17 Proportional analysis of each mood in respect to the Axé music genre 


\section{Abbreviations}

LMD: Latin Music Database; MIR: Music Information Retrieval.

\section{Competing interests}

The authors declare that they have no competing interests.

\section{Acknowledgements}

We thank the anonymous reviewers for their insightful and very valuable feedback on the earlier versions of this manuscript.

Received: 14 August 2014 Accepted: 24 July 2015

Published online: 21 August 2015

\section{References}

1. C Laurier, J Grivolla, P Herrera, in Proc. of the 7th Int. Conf. on Machine Learning and Applications. Multimodal music mood classification using audio and lyrics (San Diego, California USA, 2008), pp. 688-693

2. Y Xia, L Wang, K-F Wong, M Xu, in Proc. of the 46th Annual Meeting of the Association for Computational Linguistics on Human Language Technologies. Sentiment vector space model for lyric-based song sentiment classification (Stroudsburg, PA, USA, 2008), pp. 133-136

3. $\mathrm{H} \mathrm{He}$, J Jin, Y Xiong, B Chen, W Sun, L Zhao, in Proc. of the Int. Symp. on Intelligence Computation and Applications. Language feature mining for music emotion classification via supervised learning from lyrics (Wuhan, China, 2008), pp. 426-435. doi:10.1007/978-3-540-92137-0_47

4. Q Lu, X Chen, D Yang, J Wang, in Proc. of the 11th Int. Society for Music Information Retrieval Conference (ISMIR). Boosting for multi-modal music emotion (Utrecht, Netherlands, 2010), pp. 105-110

5. B Schuller, F Weninger, J Dorfner, in Proc. of the 12th Int. Society for Music Information Retrieval Conference (ISMIR), 2011. Multi-modal non-prototypical music mood analysis in continous space: reliability and performances (Miami, USA, 2011), pp. 759-764

6. X Wang, X Chen, D Yang, Y Wu, in Proc. of the 12th Int. Society for Music Information Retrieval Conference (ISMIR). Music emotion classification of chinese songs based on lyrics using tf*idf and rhyme (Miami, USA, 2011), pp. 765-770

7. MV Zaanen, P Kanters, in Proc. of the 11th Int. Society for Music Information Retrieval Conference (ISMIR). Automatic mood classification using tf*idf based on lyrics (Utrecht, Netherlands, 2010), pp. 75-80

8. R Mihalcea, C Strapparava, in Proc. of the Joint Conf. on Empirical Methods in Natural Language Processing and Computational Natural Language Learning. Lyrics, music and emotions (Stroudsburg, PA, USA, 2012), pp. 590-599

9. M McVicar, T Freeman, T De Bie, in Proc. of the 12th Int. Society for Music Information Retrieval Conference (ISMIR). Mining the correlation between lyrical and audio features and the emergence of mood (Miami, USA, 2011), pp. 783-788

10. X Hu, JS Downie, AF Ehmann, in Proc. of the 10th Int. Society for Music Information Retrieval Conference (ISMIR). Lyric text mining in music mood classification (Kobe, Japan, 2009), pp. 411-416

11. CN Silla Jr, AL Koerich, CAA Kaestner, in Proc. of the 9th Int. Conf. on Music Information Retrieval. The latin music database (Philadelphia, USA, 2008), pp. 451-456. https://kar.kent.ac.uk/id/eprint/24000

12. PN Juslin, P Laukka, Expression, perception, and induction of musical emotions: a review and a questionnaire study of everday listening. J. New Music Res. 33(3), 217-238 (2004)

13. D Watson, A Tellegen, Toward a consensual structure of mood. Psycollogical Bull. 98(2), 219-235 (1985)

14. JA Del Porto, Conceito e diagnóstico. Revista Brasileira de Psiquiatria, 21 (1999). doi:10.1590/S1516-44461999000500003

15. DE Bell, Putting a premium on regret. Manag. Sci. 31(1), 177-122 (1985)

16. JFV Ferreira, Romantismo: a formacão da literatura brasileira. Revista Vozes dos Vales da UFVJM. 2, 1-12 (2012)

17. J Albuquerque, M Abbud, W Kaltenbach, A Lei do Triunfo para o Século 21. (Napoleon Hill, Brazil, 2009)

18. V Caes, Existência na dimensão de pathos em kierkegaard: O conceito de paixão (pathos). Revista eletrô, nica do curso de Pedagogia das Faculdades OPET, 4 (2012). http://www.opet.com.br/faculdade/revista-pedagogia/ $\mathrm{pdf} / \mathrm{n} 4 /$ ARTIGO-VALDINEI-CAES.pdf

19. AF Magalhaes, A Psicologia do sorriso humano. (Universidade Fernando Pessoa, Brazil, 2006)
20. J-J Aucouturier, E Bigand, in Proc. of the 13th Int. Society for Music Information Retrieval Conference (ISMIR). Mel Cepstrum \& Ann Ova: The difficult dialog between MIR and music cognition (Porto, Portgual, 2012), pp. 397-402

21. Y-H Yang, X Hu, in Proc. of the 13th Int. Society for Music Information Retrieval Conference (ISMIR). Cross-cultural music mood classification: a comparison on English and Chinese songs (Porto, Portugal, 2012), pp. 19-24

22. S Brilis, E Gkatzou, A Koursoumis, K Talvis, KL Kermanidis, I Karydis, in Proc. of the IFIP Artificial Intelligence Applications and Innovations, volume 382 of IFIP Advances in Information and Communication Technology. Mood classification using lyrics and audio: a case-study in greek music (Springer, 2012), pp. 421-430. doi:10.1007/978-3-642-33412-2_43

23. B den Brinker, $R$ van Dinther, J Skowronek, Expressed music mood classification compared with valence and arousal ratings. EURASIP J. Audio Speech Music Process, 1-14 (2012). doi:10.1186/1687-4722-2012-24

24. E Brattico, V Alluri, B Bogert, T Jacobsen, N Vartiainen, S Nieminen, M Tervaniemi, A functional MRI study of happy and sad emotions in music with and without lyrics. Front. Psychol. 2, 1-16 (2011)

25. K Gfeller, DD Coffman, An investigation of emotional response of trained musicians to verbal and music information. Psycomusicology. 10(1), 31-48 (1991)

26. C Robazza, C Macaluso, V D'urso, Emotional reactions to music by gender, age, and expertise. Percept. Motor Skills. 79(2), 939-944 (1994)

27. JC Hailstone, R Omar, SMD Henley, C Frost, MG Kenward, JD Warren, It's not what you play, it's how you play it: timbre affects perception of emotion in music. Q. J. Exp. Psychol. 62(11), 2141-2155 (2009)

28. S Omar Ali, ZF Peynircioglu, Songs and emotions: are lyrics and melodies equal partners? Psychol. Music. 34, 511-534 (2006)

29. A Bhatara, AK Tirovolas, LM Duan, B Levy, DJ Levitin, Perception of emotional expression in musical performance. J. Exp. Psychol. Hum. Percept. Perform. 37(3), 921-934 (2011)

30. TEerola, JK Vuoskoski, A review of music and emotion studies: approaches, emotion models, and stimuli. Music Percep. 30(3), 307-340 (2013)

31. S Swaminathan, EG Schellenberg, Current emotion research in music psychology. Emotion Rev. 7(2), 189-197 (2015)

\section{Submit your manuscript to a SpringerOpen ${ }^{\odot}$ journal and benefit from:}

- Convenient online submission

Rigorous peer review

- Immediate publication on acceptance

- Open access: articles freely available online

- High visibility within the field

- Retaining the copyright to your article

Submit your next manuscript at $>$ springeropen.com 